\title{
PENERAPAN TEKNIK WORKSHOP PADA PEMBUATAN BLOG BAGI PEMULA DI SMA AL WASHLIYAH 12 PERBAUNGAN
}

\author{
Anita Sindar $\mathrm{RMS}^{1^{*}}$, Martua Sitorus ${ }^{2}$ \\ ${ }^{1 *}$ Teknik Informatika, STMIK Pelita Nusantara \\ ${ }^{2}$ Teknik Informatika, STMIK Pelita Nusantara \\ ${ }^{*}$ Corresponding author : \\ E-mail : haito_ita@yahoo.com
}

Diterima 26 April 2019, Disetujui 3 Mei 2019

\begin{abstract}
ABSTRAK
Materi pembuatan blog jarang diperkenalkan secara langsung di ruang kelas formal. Apabila siswa berkeinginan menambah skill bidang komputer tentunya dapat belajar sendiri. Blog dapat digunakan siswa untuk menuangkan ide, pemikiran dan tulisan. Membuat blog tidaklah sulit. Didukung template yang sudah tersedia, pembuat blog pemula lebih mudah memulai dan mengembangkannya menjadi media yang menarik yang dapat menunjang pembelajaran. Teknik pembelajaran dilaksanakan dalam bentuk workshop. Kata workshop dapat diartikan sebagai tempat berkumpulnya para pelaku aktivitas melakukan interaksi saling menjual gagasan yang ditujukan untuk memecahkan suatu permasalahan tertentu. Pembelajaran pembuatn blog dalam bentuk workshop dilakukan satu hari. Materi pembelajaran pembuatan blog difokuskan menggunakan blogger.com dan wordpress.com. Tujuan workshop untuk mendorong siswa mempergunakan fasilitas teknologi komputer yang tidak berbayar guna menambah skil dan berbagi ilmu pengetahuan. Capaian akhir diharapkan setiap siswa sudah memiliki alamat blog.
\end{abstract}

Kata kunci: pengabdian, workshop, blog, blogger, wordpress

\section{ABSTRACT}

Write Blogging material is rarely introduced directly in formal classrooms. If students want to add skills in the computer field, of course they can learn on their own. Blogs can be used by students to express ideas, thoughts and writing. Creating a blog is not difficult. Supported by available templates, beginner bloggers are easier to start and develop into interesting media that can support learning. Learning techniques are carried out in the form of workshops. The word workshop can be interpreted as a gathering place for activity actors to interact with each other to sell ideas aimed at solving a particular problem. Learning to create blogs in the form of workshops is conducted one day. Learning material for making blogs focused using blogger.com and wordpress.com. The purpose of the workshop is to encourage students to use unpaid computer technology facilities to add skills and share knowledge. The final achievement is expected that each student already has a blog address.

Keywords: service, workshop, blog, blogger, wordpress

\section{PENDAHULUAN}

Dalam menyampaikan pesan atau informasi, khususnya dalam proses belajar mengajar, diperlukan adanya media dan alat bantu pembelajaran yang akan membantu tercapainya tujuan pembelajaran. Dalam pendidikan, media berfungsi sebagai sarana fisik penyampaian materi, dan pembawa pesan. Berbagai jenis media yang dapat digunakan dalam kegiatan pembelajaran seperti : papan tulis, overhead projector, flip chart, video, film strip, LCD-projector, obyek tiga dimensi, buku teks atau modul, program komputer, dan sebagainya.

Perkembangan media sosial mempengaruhi penggunaan blog. Masyarakat cenderung menggunakan facebook saat bersosial media. Blog dapat digunakan sebagai media untuk mengekspresikan pemikiran, ide dan tulisantulisan. Blog adalah bentuk aplikasi web yang menyerupai tulisan-tulisan (dimuat dalam bentuk posting) dan biasanya dapat diakses oleh semua pengguna internet, sesuai dengan topik dan tujuan dari si pengguna blog.

Website yang menyediakan fasilitas membuat blog gratis seperti Blogger.com atau Blogspot.com, Tumblr.com, Typepad.com, Weebly.com, Wix.com, Blog.com, WordPress.com. Penyedia hosting dan domain berbayar NiagaHoster url: https://www.niagahoster.co.id/, QWords url: https://www.qwords.com/, Hosting.id url: https://www.hosting.id, Teamworks url: 
https://www.teamworks.co.id, MasterWeb url: http://www.masterweb.com/.

WordPress dan Blogspot menggunakan editor serupa untuk membuat postingan dan pages. Dapat memasukkan konten melalui editor yang tersedia dan melakukan pemformatan dasar melalui kontrol. Untuk mengontrol tampilan konten, dapat beralih ke tampilan HTML di Blogspot dan WordPress. Postingan blog dapat dipublikasikan. Blogspot baru, post dan pages dapat dikelola melalui dashboard. Blogspot, secara default, postingan baru akan ditampilkan di beranda situs web, dengan postingan terakhir ditampilkan terlebih dahulu.

Setiap url mempunyai kelebihan dan kekurangan bagi pengguna. Penggunaan blog dapat disesuaikan dengan kebutuhan, seorang pengusaha, lembaga, atau organisasi juga memanfaatkan blog untuk media beriklan seperti memperkenalkan produknya, membuat official site organisasinya, dll. Mengingat penyedia blog gratis jadi menambah efisiensi biaya iklan. Beriklan mencari uang yang dimaksud adalah dengan menjual sesuatu melalui blog atau mengikuti program seperti google adsense, dan sebagainya.

Seorang blogger harus mempunyai dasardasar ilmu komputer. Untuk mengedit harus menguasai Microsoft Word. Tujuan membuat blog bermacam-macam untuk mendokumentasi ilmunya, atau agar dapat dipelajari oleh orang lain. Seorang blogger juga sering memasukan pengalaman pribadi mereka untuk diposting di blog. Pengalaman yang dimasukan mengacu kepada pengalaman yang berbeda dan terbilang aneh atau ekstrim. Beberapa blog dirancang untuk menyediakan suatu jasa atau informasi tertentu, misalnya memberikan informasi seputar dunia komputer, menyediakan data prestasi yang pernah diraih Indonesia, jasa download film gratis, dll.

Materi pembuatan blog tidak diperkenalkan secara langsung di kelas. Orang memahami blog dengan cara belajar sendiri. Dengan memperkenalkan blog pada siswa tentu mampu mendorong para siswa lebih menguasai manfaat dari mempunyai link blog sendiri. Blog dapat dipergunakan siswa untuk merangkum materi pembelajaran, menuangkan ide-ide kreatif dalam bentuk tulisan yang dapat dibaca semua orang secara online. Hal yang menarik dari pembuatan blog yaitu memanfaatkan domain blog secara gratis. Fasilitas template (tampilan blog) dapat dipilih sesuai minat (ini dapat ganti kembali). Dalam workshop dilaksanakan, siswa akan dilatih dari pembuatan email dan cara membuat blog di blogspot. Email merupakan subfasilitas yang digunakan untuk membuat post malalui email, harus mengatur alamat Mail-to-Blogger sehingga post yang dibuat melalui email dapat terpublikasi dalam blog dan mengedit tampilan blog.

Rumusan permasalahan dalam melaksanaan pengabdian yaitu bagaimana menyelenggarakan workshop pembuatan blog pribadi dengan memanfaatkan domain blog secara gratis. Melalui blogging, banyak blogger yang telah menulis buku dan menjadikan menulis sebagai pekerjaan di website-website besar. Pembuat blog dinamakan Blogger. Melalui Blog, kepribadian Blogger menjadi mudah dikenali berdasarkan topik apa yang disukai, apa tanggapan terhadap link-link yang di pilih dan isu-isu didalamnya. Blog bersifat sangat personal.

\section{PELAKSANAAN DAN METODE}

Pelaksanaan pelatihan terlebih dahulu menetapkan secara jelas sasaran yang ingin dicapai agar mencapai target workshop. Programmed learning (pembelajaran terprogram), suatu metode sistematik untuk mengajarkan keterampilan yang mencakup penyajian pertanyaan atau fakta. Blog memuat tulisan tentang apa yang seorang Blogger pikirkan, rasakan, hingga apa yang dia lakukan sehari-hari. Blog menjadi Diary Online yang berada di Internet.

Pembelajaran bentuk workshop merupakan satu alternatif dalam mendesain model-model atau metode-metode serta strategi pembelajaran yang merupakan salah satu elemen dari unsur utama dalam mendesain pembelajaran. Workshop dapat mengubah paradigma pembelajaran dari teacher centered menuju student centered.

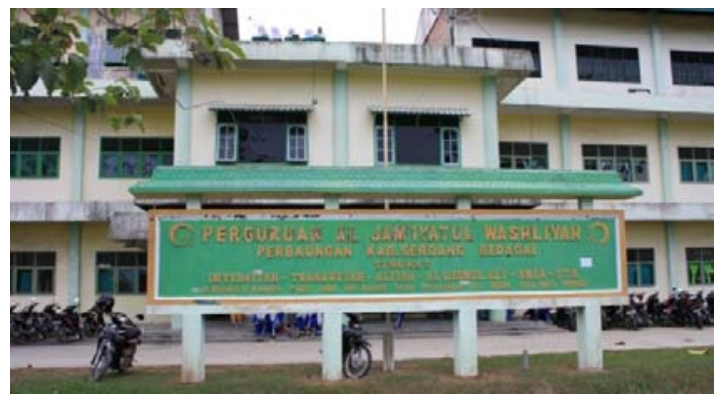

Gambar 1. SMA AL Washliyah 12 Perbaungan

Pelatihan dilaksanakan di SMA AL Washliyah 12 Perbaungan (Gambar 1), peserta berjumlah 25 siswa (Gambar 2). Penyajian materi dilaksanakan satu hari dari 08:00 pagi hingga 17:00 sore (Tabel 1 ).

Tabel 1. Schedule Workshop

\begin{tabular}{|c|c|c|}
\hline $\begin{array}{c}\text { Waktu } \\
\text { mulai }\end{array}$ & $\begin{array}{c}\text { Waktu } \\
\text { Selesai }\end{array}$ & \multicolumn{1}{|c|}{ Kegiatan } \\
\hline 08.00 & 08.30 & $\begin{array}{l}\text { Pemaparan maksud tujuan } \\
\text { dan capaian pelatihan. }\end{array}$ \\
\hline 08.30 & 11.00 & Latihan Pembuatan Blog 1 \\
\hline
\end{tabular}




\begin{tabular}{|l|c|c|}
\hline \multicolumn{3}{|c|}{ Isoma 11.00-11.30 } \\
\hline 11.30 & 14.00 & Latihan Pembuatan Blog 2 \\
\hline \multicolumn{3}{|c|}{ Isoma 14.00-14.30 } \\
\hline 15.00 & 16.30 & Pemaparan Hasil Pelatihan \\
\hline \multicolumn{3}{|c|}{ Penutupan 16.30-17.00 } \\
\hline
\end{tabular}

Materi pelatihan pembuatan blog terdiri dari pengertian Blog, Blogger, penjelasan blogger, penjelasan Wordpres, membuat blog di web hosting, membuat blog di blogger.com, membuat blog di Wordpress.

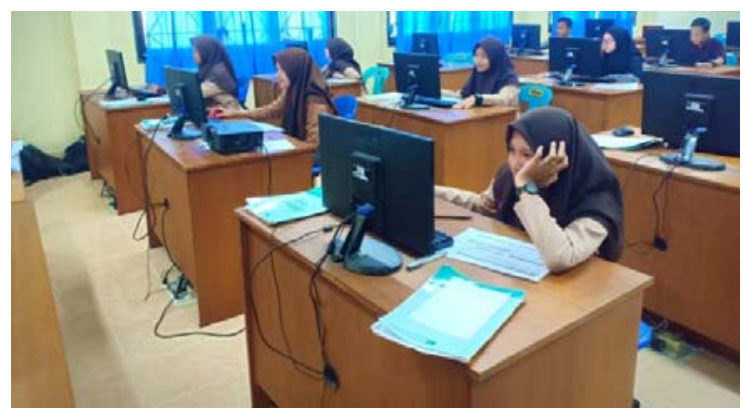

Gambar 2. Ruang Praktek Komputer

Pelatihan dimulai dengan pengarahan dari pihak sekolah mengenai maksud dan tujuan pelaksanaan berbentuk workshop. Tim pelaksana pengabdian mempersiapkan materi dalam bentuk foto copy dan pemaparan dengan slide. Instruktur/moderator pelaksanaan pelatihan yaitu Anita Sindar RMS, ST., MTI. Alat pembelajaran terdiri dari infokus dan perangkat komputer. Pada akhir sesion workshop, masing-masing siswa mengirimkan link blog yang sudah dibuat.beberpa siswa menampilkan hasil blog.

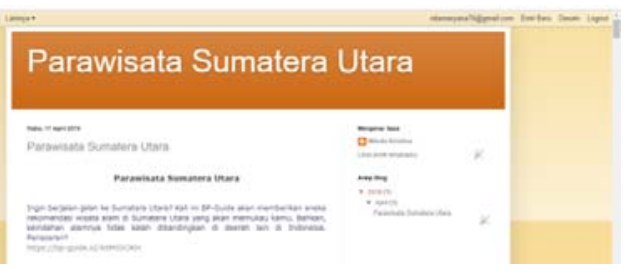

Gambar 3. Materi Workshop

Pelatihan membuat blog bertujuan :

a. Siswa mampu memahami fungsi penggunaan blog dalam meningkatkan skill bidang teknologi komputer.

b. Membuat blog sendiri dari template yang sudah tersedia.

\section{HASIL DAN PEMBAHASAN}

Pelatihan dilaksanakan dalam bentuk workshop yang menyarankan keaktifan peserta. Siswa peserta workshop dibagi menjadi 2 kelompok, satu kelompok membuat blog memanfaatkan blogger, login di www.blogger.com dan satu kelompok lagi memanfaatkan template wordpress, login pada www.wordpress.com. Ada beberapa hal yang harus dipenuhi sebelum membuat blog, yaitu account email dan koneksi internet.

Pengguna situs Wordpress dapat melakukan pendaftaran dan langsung memiliki situs tanpa perlu berhubungan dengan bahasa pemrograman web. Buka web browser arahkan URL ke http://wordpress.com. URL Wordpress berbahasa Indonesia http:/id.wordpress.com (Gambar 3). Ada beberapa tema WordPress gratis dan premium (memiliki fitur berbayar).

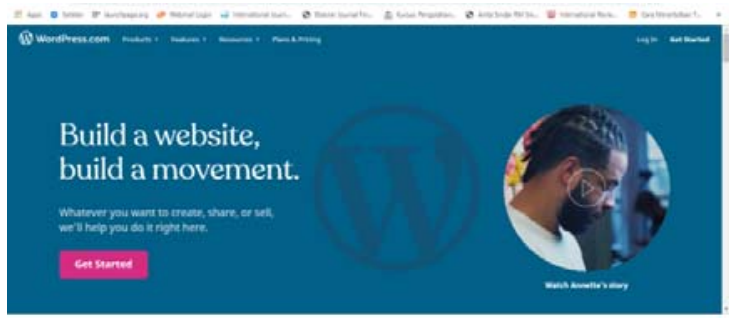

Gambar 4. Login Pada www.wordpress.com.

Bila menggunakan url blogger maka wajib mempunyai email dari google, karena blogger merupakan besutan dari google (Gambar 4).

Tabel 2. Fasilitas Tambahan Blogger

\begin{tabular}{|l|l|}
\hline \multicolumn{1}{|c|}{ Fasilitas } & \multicolumn{1}{|c|}{ Kegunaan } \\
\hline Dasar & $\begin{array}{l}\text { pengaturan dasar untuk } \\
\text { menentukan link, pencarian searh } \\
\text { engine Google, email, dan lain } \\
\text { sebagainya dalam blog. }\end{array}$ \\
\hline Feed Situs & $\begin{array}{l}\text { subfasilitas yang berfungsi } \\
\text { sebagai mesin pembaca dalam } \\
\text { blog. }\end{array}$ \\
\hline Email \& Selluler & $\begin{array}{l}\text { subfasilitas yang digunakan untuk } \\
\text { membuat post malalui email. }\end{array}$ \\
\hline OpenID & $\begin{array}{l}\text { sub fasilitas yang digunakan untuk } \\
\text { mengatur identitas orang-orang } \\
\text { yang memberikan komentar pada } \\
\text { blog }\end{array}$ \\
\hline Izin: & $\begin{array}{l}\text { subfasilitas yang berfungsi untuk } \\
\text { mengatur atau menentukan siapa } \\
\text { saja yang bisa menjadi penulis dan } \\
\text { pembaca blog }\end{array}$ \\
\hline
\end{tabular}

Fasilitas url blog yaitu ikhtisar, post, laman, komentar, spam, statistik, traffic sources, audience, tata letak, template dan setelan. Pada fasilitas Statistik dapat dilihat Overview (grafik pengunjung), Post (post yang sering dilihat), Traffic Sources, (pengunjung dari mana), Audience (asal pengunjung). 


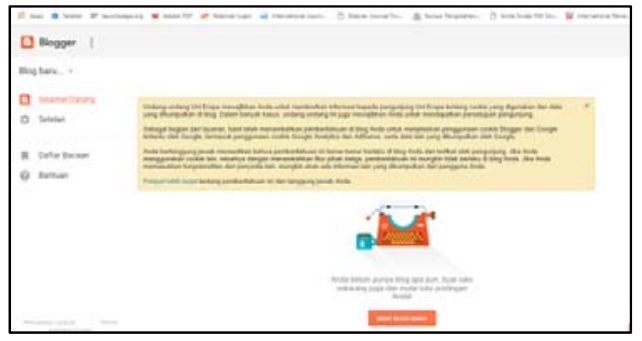

Gambar 5. Login Pada www.blogger.com

Langkah selanjutnya Klik Blog baru masukkan nama blog - pilih alamat blog, atau url pilih template - klik buat blog.

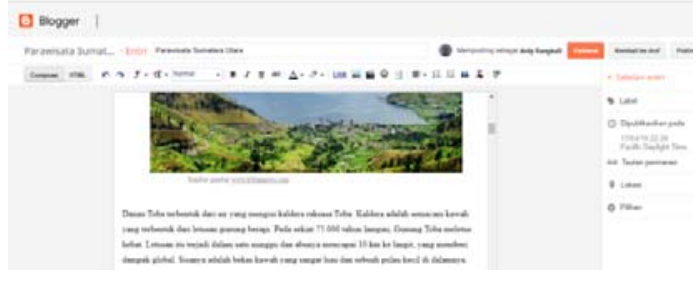

Gambar 6. Pembuatan Blog Baru

Setiap siswa mengirimkan Link blog yang telah dibuat sebagai review capaian pelatihan bagi pelaksanaan workshop, beberapa link blog siswa pada Tabel 3.

Tabel 3. Link Blog Siswa Kelas X

\begin{tabular}{|l|l|}
\hline \multicolumn{1}{|c|}{ Nama } & \multicolumn{1}{c|}{ Link } \\
\hline $\begin{array}{l}\text { Nadia } \\
\text { Pratiwi }\end{array}$ & https://designgrafik55.blogspot.com/?m=1 \\
\hline $\begin{array}{l}\text { Venen } \\
\text { Purba }\end{array}$ & https://bangpurba96.blogspot.com/ \\
\hline Anzelia & https://anzelia22.blogspot.com/ \\
\hline Muh. Rifai & https://rifaim881.blogspot.com/2018/07/ \\
\hline $\begin{array}{l}\text { Dinda } \\
\text { Tamara }\end{array}$ & https://dindatamara23.blogspot.com/?m=1 \\
\hline Friska & http://frizka94.blogspot.com/ \\
\hline Raudhatul & https://raudhatul98.wordpress.com/ \\
\hline
\end{tabular}

Untuk memasang avatar, Gambar 6, buka menu Users -> Your Profile. Pada bagian My Picture, klik Browse dan Upload Image. Tunggulah beberapa saat akan diminta crop (memotong) gambar, tipe gambar yang dapat digunakan sebagai avatar adalah JPG, GIF, atau PNG.

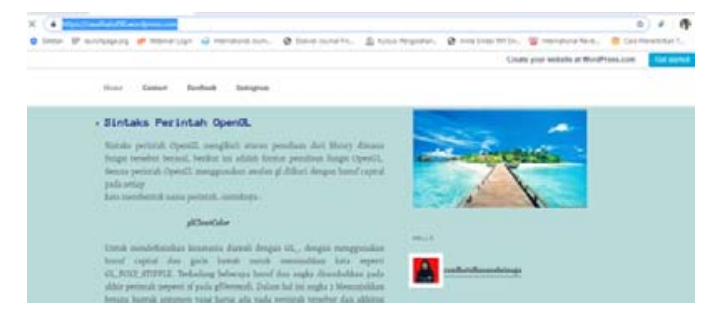

Gambar 7. Memasang Avatar Pada Wordpress

Mengedit profile, menambahkan foto, Login ke Blogger dengan memasukkan alamat email dan password Gmail. Menampilkan informasi pribadi pada blog yaitu berikan tanda centang pada kotak Nama, Uraian, Lokasi, Kota/Provinsi, Gambar 7.

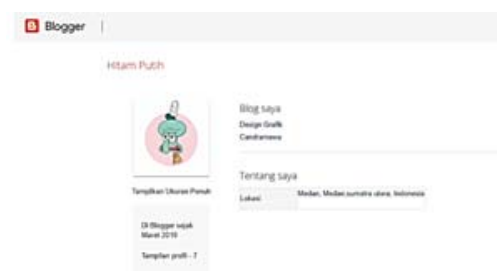

Gambar 8. Profil Blogger Pada Blogspot

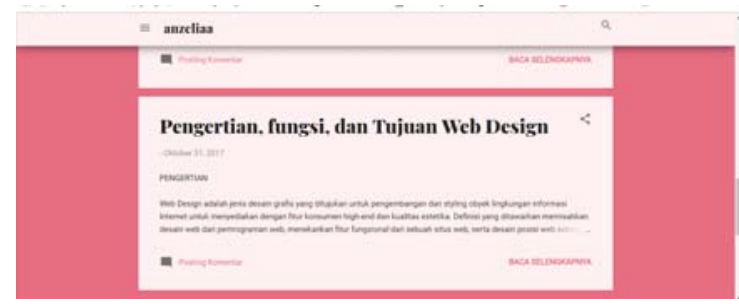

Gambar 9. Tampilan Link https://anzelia22.blogspot.com/

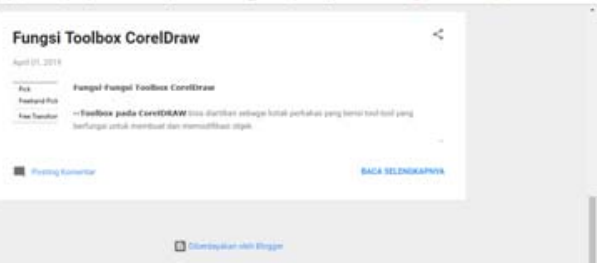

Gambar 10. Tampilan Link https://designgrafik55.blogspot.com/?m=1

\section{SIMPULAN DAN SARAN}

Dari pembelajaran praktek berbentuk workshop disimpulkan :

1. Siswa/i dapat memanfaatkan blog sebagai media berbagi ilmu, berani menampilkan ide pikiran dalam bentuk tulisan yang bermanfaat bagi orang lain mencakup materi belajar, kegemaran, pengalaman dan bidang lainnya.

2. Siswa/i membutuhkan media online untuk belajar dan berbagi ilmu.

Perkembangan teknologi berpengaruh pada pendidkan, saran bagi siswa/i yang baru memulai membuat blog :

1. Sebagai blogger pemula, siswa/i dapat memanfaatkan template blog gratis.

2. Menulis pada media blog dapat dimulai dengan berbagi tentang kegemaran dan pengalaman belajar dari siswa/i.

\section{DAFTAR RUJUKAN}

Halim Budi Santoso, Rosa Delima, Argo Wibowo, Pelatihan Pengembangan Web Profil 
Desa bagi Aparatur Pemerintah Desa, EDIMAS: Jurnal Pengabdian kepada Masyarakat, 10(1), 41-48.

Jefferly Helianthusonfri, Panduan Blogging Menghasilkan Passive Income dari Blog, Elex Media Komputindo Maret 2017.

Otodidak Membuat Blog Dengan Blogger. Jubilee Enterprise, Elex Media Komputindo, 2016.

Vitri Tundjungsari, Suhaeri, Pelatihan Pembuatan Blog untuk Pengembangan Media Pembelajaran di Sekolah Menengah Atas dan Kejuruan, JPP IPTEK, Vol. 2, No. 1 Mei 2018. 